\title{
Post-Extubation Dysphagia and Dysphonia amongst Adults with COVID-19 in the Republic of Ireland: a Prospective Multi-Site Observational Cohort Study
}

Julie Regan ${ }^{1}$, Margaret Walshe ${ }^{1}$, Sarah Lavan ${ }^{2}$, Eanna Horan ${ }^{3}$, Patricia Gillivan-Murphy ${ }^{4}$, Anne Healy ${ }^{5}$, Caoimhe Langan ${ }^{6}$, Karen Malherbe ${ }^{7}$, Breda Flynn Murphy ${ }^{8}$, Maria Cremin $^{9}$, Denise Hilton $^{10}$, Jenni Cavaliere ${ }^{11}$, and Alice Whyte ${ }^{12}$

${ }^{1}$ Trinity College Dublin

${ }^{2}$ St. James' Hospital

${ }^{3}$ Tallaght University Hospital

${ }^{4}$ Mater Misericordiae University Hospital

${ }^{5}$ Beaumont Hospital

${ }^{6}$ St Vincent's University Hospital

${ }^{7}$ Galway University Hospital

${ }^{8}$ Midland Regional Hospital Portlaoise

${ }^{9}$ University Hospital Kerry

${ }^{10}$ Cavan General Hospital

${ }^{11}$ University Hospital Waterford

${ }^{12}$ Naas General Hospital

March 22, 2021

\begin{abstract}
Objectives: This study aims to (i) investigate post-extubation dysphagia and dysphonia amongst adults intubated with SARSCOV-2 (COVID-19) and referred to speech and language therapy (SLT) in acute hospitals across the Republic of Ireland (ROI) between March and June 2020; (ii) identify variables predictive of post-extubation oral intake status and dysphonia and (iii) establish SLT rehabilitation needs and services provided to this cohort. Design: A multi-site prospective observational cohort study Participants: 100 adults with confirmed COVID-19 who were intubated across eleven acute hospital sites in ROI and who were referred to SLT services between March and June 2020 inclusive. Main Outcome Measures: Oral intake status, level of diet modification and perceptual voice quality. Results: Based on initial SLT assessment, 90\% required altered oral intake and $59 \%$ required tube feeding with $36 \%$ unable for oral intake. Age (OR 1.064; 95\% CI 1.018-1.112), proning (OR 3.671; 95\% CI 1.128-11.943), and pre-existing respiratory disease (OR 5.863; 95\% CI 1.521-11.599) were predictors of oral intake status post-extubation. Two-thirds (66\%) presented with dysphonia post-extubation. Intubation injury (OR 10.471; 95\% CI 1.060103.466) and pre-existing respiratory disease (OR 24.196; 95\% CI 1.609-363.78) were predictors of post-extubation voice quality. Thirty-seven percent required dysphagia rehabilitation post-extubation whereas $20 \%$ needed voice rehabilitation. Dysphagia and dysphonia persisted in $27 \%$ and $37 \%$ cases respectively at hospital discharge. Discussion: Post-extubation dysphagia and dysphonia were prevalent amongst adults with COVID-19 across the ROI. Predictors included iatrogenic factors and underlying respiratory disease. Prompt evaluation and intervention is needed to minimise complications and inform rehabilitation planning.
\end{abstract}

Short running title: Post-extubation dysphonia and dysphagia in COVID-19 


\title{
Post-Extubation Dysphagia and Dysphonia amongst Adults with COVID-19 in the Republic
} of Ireland: a Prospective Multi-Site Observational Cohort Study

Disclosure statement: Authors have no disclosures to report

Conflicts of interest: None

Eight key words: COVID-19; intubation; post-extubation; dysphagia; swallowing; voice; dysphonia; speech and language therapy

\begin{abstract}
Objectives: This study aims to (i) investigate post-extubation dysphagia and dysphonia amongst adults intubated with SARS-COV-2 (COVID-19) and referred to speech and language therapy (SLT) in acute hospitals across the Republic of Ireland (ROI) between March and June 2020; (ii) identify variables predictive of post-extubation oral intake status and dysphonia and (iii) establish SLT rehabilitation needs and services provided to this cohort.
\end{abstract}

Design: A multi-site prospective observational cohort study

Participants: 100 adults with confirmed COVID-19 who were intubated across eleven acute hospital sites in ROI and who were referred to SLT services between March and June 2020 inclusive.

Main Outcome Measures: Oral intake status, level of diet modification and perceptual voice quality.

Results: Based on initial SLT assessment, $90 \%$ required altered oral intake and $59 \%$ required tube feeding with $36 \%$ unable for oral intake. Age (OR 1.064; 95\% CI 1.018-1.112), proning (OR 3.671; 95\% CI 1.12811.943), and pre-existing respiratory disease (OR 5.863; 95\% CI 1.521-11.599) were predictors of oral intake status post-extubation. Two-thirds $(66 \%)$ presented with dysphonia post-extubation. Intubation injury (OR 10.471; 95\% CI 1.060-103.466) and pre-existing respiratory disease (OR 24.196; 95\% CI 1.609-363.78) were predictors of post-extubation voice quality. Thirty-seven percent required dysphagia rehabilitation postextubation whereas $20 \%$ needed voice rehabilitation. Dysphagia and dysphonia persisted in $27 \%$ and $37 \%$ cases respectively at hospital discharge.

Discussion: Post-extubation dysphagia and dysphonia were prevalent amongst adults with COVID-19 across the ROI. Predictors included iatrogenic factors and underlying respiratory disease. Prompt evaluation and intervention is needed to minimise complications and inform rehabilitation planning.

\section{Key Points}

1. Post-extubation dysphagia and dysphonia are multifactorial and can lead to prolonged ICU stay, prolonged tube feeding, aspiration pneumonia and increased morbidity and mortality.

2. In this multi-site prospective cohort study across eleven acute hospitals, $90 \%$ of adults required an altered oral diet post-extubation and $36 \%$ were unable for any oral intake based on SLT evaluation. Sixty-six percent presented with post-extubation dysphonia.

3. Age, proning and pre-existing respiratory disease were predictors of post-extubation oral intake status, whereas intubation injury and pre-existing respiratory disease were predictors of post-extubation dysphonia.

4. Over a third (37\%) required dysphagia rehabilitation post-extubation whereas $20 \%$ needed voice rehabilitation.

5. Dysphagia and dysphonia persisted in $27 \%$ and $37 \%$ cases respectively at hospital discharge, indicating that SLTs should be included in outpatient multidisciplinary COVID clinics in the community.

\section{Background}

The SARS-CoV-2 virus (termed COVID-19) is a novel respiratory virus, which has led to an international pandemic. COVID-19 has resulted in an unprecedented number of critically ill adults, which has overwhelmed 
intensive care unit (ICU) services worldwide. Endotracheal intubation and mechanical ventilation have been a central management procedure for critically ill patients with COVID-19 in ICU settings.

Post-extubation dysphagia (PED) and dysphonia are common post-extubation in critical care patients (1-4). Iatrogenic causes include prolonged intubation (5) and intubation injury including laryngeal oedema, granulations, ulceration and vocal cord immobility (6). Other potential factors are delirium (7), proning (8), disuse atrophy and critical illness neuropathy or myopathy during ICU stay (9) and neurological manifestations of COVID-19 (10). Also, tracheostomy insertion can lead to aspiration risk and difficulties managing secretions (3). PED is associated with worse outcomes in ICU including aspiration pneumonia, prolonged tube feeding, delayed initiation of oral intake, prolonged hospitalisation, and increased morbidity and mortality $(11,12)$.

Dysphonia is another recognised complication of intubation reported amongst adults with COVID-19 (3). Post-extubation dysphonia results from vocal cord immobility, laryngopharyngeal reflux, granuloma, reduced breath support for phonation and vocal cord fatigue. Endotracheal tube (ETT) size (13) and cuff pressure during intubation (14) have been identified as risk factors for post-extubation dysphonia. Age and duration of intubation has also been linked with prolonged dysphonia post-extubation in previous critical care research (15).

The impact of intubation as part of COVID-19 management on swallowing and voice is unclear internationally, as are the dysphagia and dysphonia rehabilitation needs within this population (16). This study aims to characterise the presence and degree of post-extubation voice and swallowing difficulties amongst adults requiring intubation as part of medical management of COVID-19 in the Republic of Ireland (ROI) during the first wave of the pandemic. Specific research objectives are to (i) explore the presence, degree and trajectory of dysphonia and dysphagia post-extubation in adults with COVID-19 across the ROI between March and June 2020 inclusive; (ii) identify variables, which predict post-extubation oral intake status and voice quality, and (iii) determine SLT evaluation and rehabilitation indicated and provided to this cohort.

\section{Methods}

\section{Study Design}

This multi-site prospective observational cohort study is reported according to the STROBE guidelines for observational cohort studies (17). Ethical approval for this study was obtained from National Research Ethics Committee (NREC).

\section{Settings}

In this multi-centre observational cohort study, speech and language therapists from eleven acute hospitals across Ireland participated.

\section{Participants}

All adults admitted into a participating acute hospital in the ROI with COVID-19 and referred to SLT were included. Inclusion criteria were (i) confirmed COVID-19 positive based on polymerase chain reaction (PCR) test; (ii) intubated during inpatient stay as part of COVID-19 treatment; (iii) referred to SLT during hospital admission and (iv) consent obtained. Exclusion criteria were (i) age 16 years or younger (ii) unconfirmed COVID-19; (iii) no consent (iv) intubation for reasons other than COVID-19.

\section{Independent Variables}

Demographic data included age, gender, pre-admission medical comorbidities and premorbid swallow status. During hospital admission, data on neurological manifestations of COVID-19 were captured. The patient's most recent chest x-ray at time of initial SLT assessment was rated using a validated five-point ordinal scoring system (18).

Intubation variables collated from healthcare records were grade of intubation (1-4), number of endo-tracheal tubes (ETT) used, maximum ETT cuff pressure during intubation, number of failed extubations and presence of intubation injury. Data on proning and proning-related injury were collected. Tracheostomy insertion, 
tracheostomy type and size, time to decannulation were also included. Length of ICU stay (LOSICU) and hospital length of stay (LOS) were recorded.

\section{Swallow and Voice Outcomes}

Swallowing and voice outcomes were influenced by curtailed access during COVID-19 to instrumental assessments typically used in intensive care settings such as fibreoptic endoscopic evaluation of swallowing (FEES). Presence and severity of PED was measured using the Functional Oral Intake Scale (FOIS) (19). The FOIS is a validated 7-point ordinal rating scale with high inter-rater reliability (19). A second proxy dysphagia measure was food and fluid consistencies required for dysphagia management, using the International Dysphagia Diet Standardisation Initiative (IDDSI) (20). Voice quality was evaluated using the overall Grade (G) score from the GRBAS scale (21). The scale has established high rater reliability (21) and is widely used in clinical research (12).

\section{Data Sources/Management}

One nominated speech and language therapist from each hospital site was responsible for data entry at each location. A dataset and dataset dictionary were emailed to named speech and language therapists from each participating site. Speech and language therapists were instructed to populate the dataset prospectively and return the anonymised data to the first authors for analysis.

\section{Bias}

To minimise observer bias, all clinicians used outcome measures routinely used in clinical practice with established rater reliability. Clear rules and procedures were in place for data collection and data were clearly defined in a data dictionary provided to all settings. Merged data was anonymised to researchers.

\section{Study Size}

Any patients who meet the eligibility criteria over the three-month data collection period were included in the study. The study size was determined by the prevalence of cases, and in particular those needing respiratory support. In the event, 100 participants were recruited with the precision in the statistical estimates illustrating the observed power.

\section{Statistical Analysis}

Descriptive statistics were reported using medians and interquartile range (IQR) for continuous data. Categorical variables were presented as frequency (percentage). Variables were tested for normality using the Shapiro-Wilks test. To establish associations between dependent and independent variables, Spearman's rho correlations were conducted. To determine the trajectory of dysphagia and dysphonia from initial SLT assessment to SLT discharge, medians of ordinal dependent variables at both time points were compared using two-tailed Wilcoxon signed rank tests.

To determine independent predictors of oral intake status at time of initial SLT assessment, a binary logistic regression was used. The seven-point ordinal FOIS rating scale was divided into feeding tube reliant (FOIS Levels 1-3) and not tube feeding reliant (FOIS Level 4-7) categories as the binary dependent variable. To prevent over-fitting the model, six independent variables were selected for oral intake status (age, duration of intubation, proning, neurological manifestations, maximum cuff pressure, history of respiratory disease).

For voice quality, an ordinal logistic regression was completed with the overall (G) four-point ordinal GRBAS rating as the dependent variable. Six independent variables were selected for the voice regression model (intubation injury, proning, maximum cuff pressure, duration of intubation, number of comorbidities, and history of respiratory disease).

For both regression models, independent variables were selected based on evidence from previous research and a visual review of the data. Where a significant association was identified between independent variables (e.g., duration of intubation and presence of tracheostomy), only one was selected for a model. Mean imputation was made for one independent variable (maximum cuff pressure) as it was missing 24/100 cases. Model 
fits were confirmed using likelihood ratio chi- squared tests. A two-sided $\alpha$ of less than 0.05 was considered statistically significant. Statistical analyses were completed using the SPSS (v26) software.

\section{Results}

\section{Participants}

Data from 100 adults with PCR test confirmed COVID-19 who were intubated across eleven acute hospitals in ROI and referred to SLT between March and June 2020 inclusive were included in analysis. The 100 adults (69\% male) had a mean age of 62 years (age range 17-88 years). Further demographic details are in Table 1.

\section{TABLE 1 HERE}

Median duration of intubation was 14 days (IQR 8-19.5). Data on grade of intubation, number of ET tubes, maximum cuff pressure (76/100), number of failed extubations, proning and tracheostomy are captured in Table 1. Missing data for some of these variables was due to limited access to data across clinical settings.

TABLE 2 HERE

\section{Presence, Severity and Trajectory of Swallowing and Voice Outcomes Post-Extubation}

Median time between extubation and initial SLT evaluation was 4 days (IQR 2-11 days). Ninety percent $(\mathrm{n}=90)$ of patients presented with dysphagia (FOIS Level 1-6) at initial SLT assessment with $36 \%$ unable to take any nutrition orally (FOIS Level 1) (Table 3). Median FOIS score at initial SLT assessment was 2.5 (SD 2.139; range 1-7) ( $\mathrm{n}=100)$. IDDSI fluid and food consistency findings are detailed in Table 3. A significant negative correlation was observed between oral intake status at initial SLT assessment as rated by the FOIS and ICULOS $(\mathrm{r}=-.227 ; \mathrm{p}=0.028)$ and also between oral intake status and hospital LOS, indicating that the lower the FOIS score, the longer the LOS $(\mathrm{r}=-.363 ; \mathrm{p}=0.000)$.

Two-thirds $(66 \% ; \mathrm{n}=99)$ of participants presented with post-extubation dysphonia (GRBAS $1 /+$ ) with $14 \%$ in severe (rating 3) category (Table 3). A weak positive association was detected between GRBAS rating and LOS ( $\mathrm{r}=.235 ; \mathrm{p}=022$ ), indicating that the higher the GRBAS score (poor vocal quality), the longer the hospital LOS. Voice quality was not associated with ICULOS $(\mathrm{r}=.084 ; \mathrm{p}=0.428)$.

Oral intake status (median FOIS score) altered significantly from initial SLT assessment (FOIS score 2.5) to time of SLT discharge (median FOIS score 7$)(\mathrm{z}=-7.322 ; \mathrm{p}=0.000)$. A significant change was also observed in IDDSI fluid $(\mathrm{z}=-6.023 ; \mathrm{p}=0.000)$ and food $(\mathrm{z}=-7.52 ; \mathrm{p}=0.000)$ consistencies within the participant group from initial assessment to discharge (Table 3 ).

\section{Table 3 here}

Median voice quality rating also altered significantly from initial SLT assessment (GRBAS score 1) to SLT discharge (GRBAS score 0$)(\mathrm{z}=-5.619 ; \mathrm{p}=0.000)$. Details regarding alteration in swallow and voice outcomes are in Table 3.

\section{Variables Predicting Dysphagia and Dysphonia at Initial SLT Assessment}

\section{Table 4 here}

In a multivariate model, statistically significant predictors of post-extubation oral intake status included age (OR 1.064; 95\% CI 1.018-1.112; $\mathrm{p}=0.006$ ), proning (OR 3.671; 95\% CI 1.128-11.943; $\mathrm{p}=.031$ ), and history of respiratory disease (OR 5.863; 95\% CI 1.521-22.599; $\mathrm{p}=.010$ ) (Table 4).

\section{Table 5 here}

In a multivariate model, statistically significant predictors of post-extubation voice quality were intubation injury (OR 10.471; CI 1.060-103.466; p=.044) and history of respiratory disease (OR 24.196; 95\% CI 1.609363.78; $\mathrm{p}=.021$ ) (Table 5). 


\section{SLT Rehabilitation Needs and Services Provided}

Over a third $(\mathrm{n}=37 / 100)$ of patients required dysphagia rehabilitation post-extubation (Table 6$)$. In $70 \%$ $(26 / 37)$ of these cases, dysphagia rehabilitation was implemented, although $19 \%(7 / 37)$ had it provided in adapted form due to infection risk related to the pandemic. In $11 \%(4 / 37)$ of cases, dysphagia rehabilitation was indicated but could not be provided at point of service delivery due to the pandemic service constraints. A fifth $(20 \% ; n=20 / 100)$ of participants required voice rehabilitation post-extubation. Within this subgroup, $55 \%(11 / 20)$ received standard voice rehabilitation and $15 \%(3 / 20)$ received it in adapted form (Table 6$)$. In $30 \%(6 / 20)$ cases, voice rehabilitation was indicated but could not be implemented also due to pandemic service constraints.

\section{Table 6 here}

\section{Discussion}

In this study, $90 \%$ of patients intubated as part of COVID-19 management across the ROI who were referred to SLT presented with new onset PED based on oral intake status. Over half (59\%) required tube feeding based on SLT assessment and over a third were unable for any nutrition orally post-extubation. This high rate of PED compares with recent research $(3,4)$. Post-extubation oral intake status was associated with length of ICU stay and hospital stay duration in this study.

There was a threefold increase in impact on oral intake status with proning in this study. Lower cranial nerve paralysis and oropharyngeal oedema have previously been linked to proning, and cranial nerves IX to XII are hypothesised to be affected by proning $(7,23)$. Pre-existing respiratory disease was also identified as a predictor of PED in this study. Adults with respiratory disease may already have altered respiratory swallow coordination, which could be exacerbated post-extubation. There was approximately a $6 \%$ increase in the relative odds of oral intake status change per year of age in this study. Older people may have a pre-existing presbyphagia, which pre-disposes them to PED. Furthermore, frailty and sarcopaenia may also be prevalent amongst older people, which could contribute towards PED. In contrast to previous research (5), duration of intubation was not predictive of oral intake status in this study. This may be due to the fact that patients with tracheostomy were not excluded in this study, as researchers aimed to capture all adults with COVID-19 post extubation. Additionally, prolonged intubation duration with COVID-19 may explain contrasting findings to previous PED research.

There was a tenfold increase in impact on voice quality for those with intubation injury, which aligns with previous research (15). This highlights the importance of post-extubation endoscopy to evaluate vocal cord function in the ICU setting. Those with a history of respiratory disease were at threefold risk of impact on voice quality. Dysphonia is prevalent in adults with COPD which is due, in part, to altered pulmonary function (24). This alteration may be exacerbated post-extubation, which may negatively impact on voice. In contrast to previous research (14), endotracheal cuff pressure was not associated with post-extubation dysphonia in this study.

The number of adults receiving SLT rehabilitation during hospital stay appeared low in this study and some adults did not receive dysphagia and dysphonia intervention when indicated. Concerns regarding aerosol generated procedures as well as lack of instrumental evaluations may have influenced the amount and type of intervention being offered during the first pandemic wave (16). Other influencing factors may be access to personal protective equipment, SLT services in ICU settings across ROI, and local dysphagia training.

The rates of persistent dysphagia and dysphonia at hospital discharge mirrors previous COVID-19 research $(3,4)$. These subgroups may require long term rehabilitation due to ICU acquired weakness, post-intensive care syndrome (PICU) or neurological deficits. These figures are clear evidence that speech and language therapists should be core members of outpatient multidisciplinary COVID-19 clinics.

Limitations to this study included missing data on oral health, delirium, grade of intubation and endotracheal tube size. Missing data was particularly difficult to access from intensive care records due to transmission risk. Patient reported outcomes would have been beneficial but not feasible post-extubation given how medically 
unwell this cohort were. Validated scales to measure frailty and sarcopaenia amongst adults intubated may have been useful but again this was not feasible in the context of this study.

FEES was not available in ICU settings during the first wave of the pandemic due to concerns regarding transmission risk (16). FEES provides physiological data on secretions, pharyngeal sensation and aspiration or residue. However, it could be argued that oral intake is a more meaningful outcome from the patient perspective. Nevertheless, endoscopic assessment of intubation injury would be valuable to ensure the presence and nature of laryngeal injuries are accurately identified (25).

Post-extubation dysphonia and dysphagia research is needed from future pandemic waves to establish the impact of evolving intensive care management and mutating virus variants on voice and swallowing outcomes. Post-discharge timepoints to capture longer term voice and swallowing difficulties would guide multidisciplinary service delivery in the community.

\section{Conclusions}

This study highlights the prevalence of post-extubation dysphagia and dysphonia amongst adults intubated with COVID-19. Awareness of the predictors of altered swallowing and voice quality post-extubation will promote early in-depth evaluation and monitoring during hospital stay. Prompt dysphagia and dysphonia evaluation and management is needed to minimise clinical and quality of life complications.

\section{References}

1. Brodsky, M. B., Nollet, J. L., Spronk, P. E., \& González-Fernández, M. (2020). Prevalence, Pathophysiology, Diagnostic Modalities and Treatment Options for Dysphagia in Critically Ill Patients. American Journal of Physical Medicine 83 Rehabilitation .

2. Hamdan, A. L., Sibai, A., Rameh, C., \& Kanazeh, G. (2007). Short-term effects of endotracheal intubation on voice. Journal of Voice, 21 (6), 762-768.

3. Archer SK, Iezzi CM, Gilpin L, Swallowing and voice outcomes in patients hospitalised with COVID-19: An observational cohort study, ARCHIVES OF PHYSICAL MEDICINE AND REHABILITATION (2021) Brodsky, M. B., Gellar, J. E., Dinglas, V. D., Colantuoni, E., Mendez-Tellez, P. A., Shanholtz, C., ... \& Needham, D. M. (2014). Duration of oral endotracheal intubation is associated with dysphagia symptoms in acute lung injury patients. Journal of critical care, 29 (4), 574-579.

4. Dawson, C., Capewell, R., Ellis, S., Matthews, S., Adamson, S., Wood, M., .. \& \& Sharma, N. (2020). Dysphagia presentation and management following COVID-19: an acute care tertiary centre experience. The Journal of Laryngology \& Otology , 1-6.

5. Brodsky, M. B., Levy, M. J., Jedlanek, E., Pandian, V., Blackford, B., Price, C., .. \& \& Akst, L. M. (2018). Laryngeal injury and upper airway symptoms after oral endotracheal intubation with mechanical ventilation during critical care: a systematic review. Critical care medicine , 46 (12), 2010.

6. O'Hanlon S, Inouye SK. Delirium: a missing piece in the COVID-19 pandemic puzzle. Age and ageing. 2020 May 6.

7. Brugliera L, Filippi M, Del Carro U, Butera C, Bianchi F, Castellazzi P, Cimino P, Capodaglio P, Monti G, Mortini P, Pradotto LG. Nerve Compression Injuries After Prolonged Prone Position Ventilation in Patients With SARS-CoV-2: A Case Series. Archives of Physical Medicine and Rehabilitation. 2021 Jan 1.

8. Ponfick M, Linden R, Nowak DA. Dysphagia - a common, transient symptom in critical illness polyneuropathy: a fiberoptic endoscopic evaluation of swallowing study. Critical care medicine. 2015 Feb $1 ; 43(2): 365-72$.

9. Dziewas, R., Warnecke, T., Zürcher, P., \& Schefold, J. C. (2020). Dysphagia in COVID-19-multilevel damage to the swallowing network? European journal of neurology .

10. McGrath BA, Brenner MJ, Warrillow SJ, Pandian V, Arora A, Cameron TS, Anon JM, Martinez GH, Truog RD, Block SD, Lui GC. Tracheostomy in the COVID-19 era: global and multidisciplinary guidance. The Lancet Respiratory Medicine. 2020 May 15.

11. Macht, M., King, C. J., Wimbish, T., Clark, B. J., Benson, A. B., Burnham, E. L., .. \& \& Moss, 
M. (2013). Post-extubation dysphagia is associated with longer hospitalization in survivors of critical illness with neurologic impairment. Critical Care ,17 (3), 1-9.

12. Brodsky, M. B., Huang, M., Shanholtz, C., Mendez-Tellez, P. A., Palmer, J. B., Colantuoni, E., \& Needham, D. M. (2017). Recovery from dysphagia symptoms after oral endotracheal intubation in acute respiratory distress syndrome survivors. A 5-year longitudinal study. Annals of the American Thoracic Society , 14 (3), 376-383.

13. Krisciunas, G. P., Langmore, S. E., Gomez-Taborda, S., Fink, D., Levitt, J. E., McKeehan, J., .. \& Vojnik, R. (2020). The Association Between Endotracheal Tube Size and Aspiration (During Flexible Endoscopic Evaluation of Swallowing) in Acute Respiratory Failure Survivors. Critical Care Medicine , 48 (11), 1604-1611.

14. SAMY, A., NEFISSA, A., \& AZZAM, A. E. A. (2018). Voice Disorders after Intubation: The Importance of Intra-Operative Monitoring and Controlling of Endo-Tracheal Tube Cuff Pressure in Reducing Intubation-Related Complications. The Medical Journal of Cairo University , 86 (September), 28492860.

15. Yamanaka, H., Hayashi, Y., Watanabe, Y., Uematu, H., \& Mashimo, T. (2009). Prolonged hoarseness and arytenoid cartilage dislocation after tracheal intubation. British journal of anaesthesia, 103 (3), $452-455$.

16. Freeman-Sanderson A, Ward EC, Miles A, de Pedro Netto I, Duncan S, Inamoto Y, McRae J, Pillay N, Skoretz SA, Walshe M, Brodsky MB. A consensus statement for the management and rehabilitation of communication and swallowing function in the ICU: A global response to COVID-19. Archives of physical medicine and rehabilitation. 2020 Nov 7.

17. Von Elm, E., Altman, D. G., Egger, M., Pocock, S. J., Gotzsche, P. C., Vandenbroucke, J. P., \& Strobe Initiative. (2014). The Strengthening the Reporting of Observational Studies in Epidemiology (STROBE) Statement: guidelines for reporting observational studies. International journal of surgery , 12 (12), 1495-1499.

18. Taylor, E., Haven, K., Reed, P., Bissielo, A., Harvey, D., McArthur, C., .. \& \& Wilson, F. (2015). A chest radiograph scoring system in patients with severe acute respiratory infection: a validation study. BMC medical imaging, 15 (1), 61.

19. Crary, M. A., Mann, G. D. C., \& Groher, M. E. (2005). Initial psychometric assessment of a functional oral intake scale for dysphagia in stroke patients. Archives of physical medicine and rehabilitation , 86 (8), 1516-1520.

20. Cichero, J. A., Lam, P., Steele, C. M., Hanson, B., Chen, J., Dantas, R. O., .. \& Stanschus, S. (2017). Development of international terminology and definitions for texture-modified foods and thickened fluids used in dysphagia management: the IDDSI framework.Dysphagia , 32 (2), 293-314.

21. Hirano M. Clinical examination of voice. New York: Springer Verlag, 1981:81-4

22. Karnell, M. P., Melton, S. D., Childes, J. M., Coleman, T. C., Dailey, S. A., \& Hoffman, H. T. (2007). Reliability of clinician-based (GRBAS and CAPE-V) and patient-based (V-RQOL and IPVI) documentation of voice disorders. Journal of Voice , 21 (5), 576-590.

23. Le MQ, Rosales R, Shapiro LT, Huang LY. The Down Side of Prone Positioning: The Case of a COVID-19 Survivor. American Journal of Physical Medicine \& Rehabilitation. 2020 Jul 9.

24. Hassan MM, Hussein MT, Emam AM, Rashad UM, Rezk I. Is insufficient pulmonary air support the cause of dysphonia in chronic obstructive pulmonary disease? Auris Nasus Larynx. 2018 Aug 1;45(4):807-14.

25. Naunheim, M. R., Zhou, A. S., Puka, E., Franco Jr, R. A., Carroll, T. L., Teng, S. E., .. \& Song, P. C. Laryngeal complications of COVID-19. Laryngoscope Investigative Otolaryngology .

Table 1. Demographic Data

\begin{tabular}{lll}
\hline Age & Mean Range & 62 years 17-88 years \\
\hline Gender & Males Females & 69 males 31 females
\end{tabular}




\begin{tabular}{|c|c|c|}
\hline Age & Mean Range & 62 years $17-88$ years \\
\hline Source of admission & $\begin{array}{l}\text { Home Residential setting Transfer } \\
\text { from other hospital Transfer from } \\
\text { rehab setting Unknown }\end{array}$ & $81 \% 2 \% 14 \% 1 \% 2 \%$ \\
\hline Co-morbidities & $\begin{array}{l}\text { None Minimum one comorbidity: } \\
\text { One comorbidity Two Three Four } \\
\text { Five Mean/median no of } \\
\text { comorbidities: Medical } \\
\text { comorbidities: Respiratory disease } \\
\text { (COPD/other respiratory disease) } \\
\text { Cardiology Stroke Progressive } \\
\text { neurological Dementia Mental } \\
\text { health condition Head and neck } \\
\text { cancer Cancer outside of head and } \\
\text { neck Diabetes Obesity Intellectual } \\
\text { disability Other }\end{array}$ & 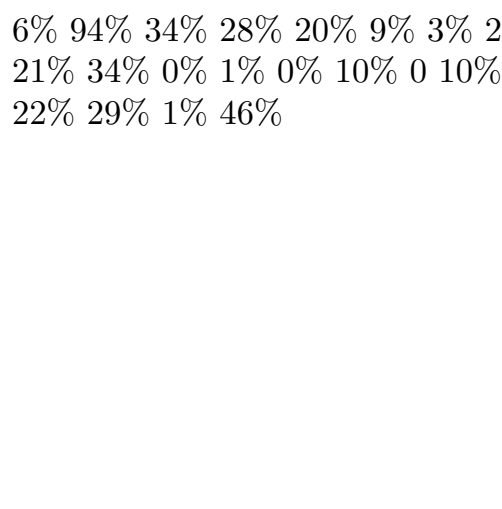 \\
\hline Pre-admission swallow status & $\begin{array}{l}\text { Normal diet (FOIS Level 7) FOIS } \\
\text { Level } 5 \text { FOIS Level } 1\end{array}$ & $96 \% 3 \% 1 \%$ \\
\hline $\begin{array}{l}\text { COVID-19 Neurological } \\
\text { manifestations }\end{array}$ & $\begin{array}{l}\text { Total: Stroke } n=2 \text { Seizures } n=1 \\
\text { Impaired consciousness } n=20 \\
\text { Delirium } n=8\end{array}$ & $37 \%(34 / 96)$ \\
\hline $\begin{array}{l}\text { Most recent Chest x-ray at } \\
\text { time of SLT initial } \\
\text { assessment }\end{array}$ & $\begin{array}{l}\text { Abnormal Chest x-ray } \\
\text { classification (Taylor et al, } \\
\text { 2015): Patchy atelectasis } \\
\text { and/bronchial wall thickening } \\
\text { Focal consolidation Multifocal } \\
\text { consolidation Diffuse alveolar } \\
\text { changes Unknown }\end{array}$ & $99 \% 8 \% 8 \% 74 \% 2 \% 1 \%$ \\
\hline
\end{tabular}

Table 2. Ventilation Data

Intubation details (where data is missing it is because data could not be obtained from local healthcare records)

Intubat Stridor Vocal co Other $\mathbf{P}$ Pressure Lip lacer Herpes $r$ Ulcer on

Table 3.

Trajectory of Swallow and Voice Outcomes from Initial Assessment to SLT Discharge

Oral Intake Status

(Functional Oral Intake Initial SLT Assessment

Scale $) \quad(n=100) \quad$ Discharge $(n=95)$

1: Tube dependent.

$36 \quad 4$

Nothing by mouth. 


\begin{tabular}{|c|c|c|}
\hline $\begin{array}{l}\text { Oral Intake Status } \\
\text { (Functional Oral Intake } \\
\text { Scale) }\end{array}$ & $\begin{array}{l}\text { Initial SLT Assessment } \\
(n=100)\end{array}$ & Discharge $(n=95)$ \\
\hline $\begin{array}{l}\text { 2: Tube dependent with } \\
\text { minimal attempts at food } \\
\text { or or liquid. }\end{array}$ & 14 & 0 \\
\hline $\begin{array}{l}\text { 3: Tube dependent with } \\
\text { consistent oral intake of } \\
\text { food or liquid. }\end{array}$ & 9 & 0 \\
\hline $\begin{array}{l}\text { 4: Total oral diet of a single } \\
\text { consistency }\end{array}$ & 2 & 0 \\
\hline $\begin{array}{l}\text { 5: Total oral diet with } \\
\text { multiple consistencies, but } \\
\text { requiring special } \\
\text { preparation or } \\
\text { compensations. }\end{array}$ & 25 & 10 \\
\hline $\begin{array}{l}\text { 6: Total oral diet with } \\
\text { multiple consistencies } \\
\text { without special } \\
\text { preparation, but with } \\
\text { specific food limitations. }\end{array}$ & 4 & 8 \\
\hline $\begin{array}{l}\text { 7: Total oral diet with no } \\
\text { restrictions }\end{array}$ & 10 & 73 \\
\hline Median (IQR) & $2.5(1-5)$ & $7(7-7)$ \\
\hline $\mathrm{Z}$ score ( $\mathrm{p}$ value) & $-7.322(\mathrm{p}=.000)$ & $-7.322(\mathrm{p}=.000)$ \\
\hline $\begin{array}{l}\text { Fluid Consistency (IDDSI } \\
\text { Fluid Consistencies) }\end{array}$ & $\begin{array}{l}\text { Initial SLT Assessment } \\
(n=100)\end{array}$ & Discharge $(n=91)$ \\
\hline 0: Thin fluid & 43 & 85 \\
\hline 1: Slightly thick fluid & 12 & 5 \\
\hline 2: Mildly thick fluid & 11 & 1 \\
\hline 3: Moderately thick fluid & 1 & - \\
\hline 4: Extremely thick fluid & 3 & - \\
\hline 5: No fluids & 30 & - \\
\hline Median (IQR) & $1(0-5)$ & $0(0-0)$ \\
\hline $\mathrm{Z}$ score ( $\mathrm{p}$ value) & $-6.023(\mathrm{p}=.000)$ & $-6.023(\mathrm{p}=.000)$ \\
\hline $\begin{array}{l}\text { Food consistency (IDDSI } \\
\text { Food Consistencies) }\end{array}$ & $\begin{array}{l}\text { Initial SLT Assessment } \\
(n=100)\end{array}$ & Discharge $(n=91)$ \\
\hline 4: Puree & 21 & 2 \\
\hline 5: Minced and moist & 15 & 1 \\
\hline 6: Soft \& bite sized & 12 & 9 \\
\hline 7: Regular & 12 & 78 \\
\hline 0: (none) & 40 & 1 \\
\hline Median (IQR) & $4(0-5)$ & $7(7-7)$ \\
\hline $\mathrm{Z}$ score ( $\mathrm{p}$ value) & $-8.976(p=.000)$ & $-8.976(p=.000)$ \\
\hline Voice Quality (GRBAS- G) & $\begin{array}{l}\text { Initial SLT Assessment } \\
(n=99)\end{array}$ & Discharge $(n=83)$ \\
\hline 0: No abnormality detected & 34 & 63 \\
\hline 1: Mild & 31 & 12 \\
\hline 2: Moderate & 20 & 7 \\
\hline 3: Severe & 14 & 1 \\
\hline Median (IQR) & $1(0-2)$ & $0(0-0)$ \\
\hline
\end{tabular}


Oral Intake Status

(Functional Oral Intake Initial SLT Assessment

\begin{tabular}{lll} 
Scale $)$ & $(\mathbf{n = 1 0 0})$ & Discharge $(\mathbf{n}=\mathbf{9 5})$ \\
\hline $\mathbf{Z}$ score $(\mathbf{p}$ value $)$ & $-5.619(\mathrm{p}=.000)$ & $-5.619(\mathrm{p}=.000)$ \\
\hline
\end{tabular}

Table 4. Independent Variables Predictive of Post-Extubation Oral intake status

\begin{tabular}{|c|c|c|c|c|c|c|}
\hline $\begin{array}{l}\text { Independent } \\
\text { Variable }\end{array}$ & B & SE & Odds ratio & $\begin{array}{l}95 \% \text { CI for } \\
\text { OR Lower } \\
\text { Upper }\end{array}$ & $\begin{array}{l}95 \% \text { CI for } \\
\text { OR Lower } \\
\text { Upper }\end{array}$ & $\mathbf{P}$ value \\
\hline Age & .062 & .0225 & 1.064 & 1.018 & 1.112 & $.006^{*}$ \\
\hline $\begin{array}{l}\text { Maximum } \\
\text { cuff pressure }\end{array}$ & -.001 & .0448 & .999 & .915 & 1.091 & .988 \\
\hline Proning & 1.300 & .6019 & 3.671 & 1.128 & 11.943 & $.031^{*}$ \\
\hline $\begin{array}{l}\text { Neurological } \\
\text { manifestations }\end{array}$ & 1.049 & .5804 & .2856 & .915 & 8.907 & .071 \\
\hline $\begin{array}{l}\text { History of } \\
\text { respiratory } \\
\text { disease }\end{array}$ & 1.769 & .6884 & 5.863 & 1.521 & 11.599 & $.01^{*}$ \\
\hline $\begin{array}{l}\text { Duration of } \\
\text { intubation }\end{array}$ & -.860 & .5381 & .423 & .147 & 1.215 & .110 \\
\hline
\end{tabular}

Table 5. Independent Variables Predictive of Post-Extubation Voice Quality

\begin{tabular}{|c|c|c|c|c|c|c|}
\hline $\begin{array}{l}\text { Independent } \\
\text { Variable }\end{array}$ & B & SE & Odds ratio & $\begin{array}{l}95 \% \text { CI for } \\
\text { OR Lower } \\
\text { Upper }\end{array}$ & $\begin{array}{l}95 \% \text { CI for } \\
\text { OR Lower } \\
\text { Upper }\end{array}$ & $\mathbf{P}$ value \\
\hline $\begin{array}{l}\text { Intubation } \\
\text { injury }\end{array}$ & 2.349 & 1.1687 & 10.471 & 1.060 & 103.466 & $.044^{*}$ \\
\hline $\begin{array}{l}\text { Number of } \\
\text { comorbidities }\end{array}$ & -.310 & .5136 & .733 & .268 & 2.007 & .546 \\
\hline Proning & 1.328 & .9441 & 3.775 & .593 & 24.015 & .159 \\
\hline $\begin{array}{l}\text { Maximum } \\
\text { cuff pressure }\end{array}$ & -.087 & .0697 & .916 & .799 & 1.050 & .209 \\
\hline $\begin{array}{l}\text { Duration of } \\
\text { intubation }\end{array}$ & -.113 & .0668 & .893 & .784 & 1.018 & .091 \\
\hline $\begin{array}{l}\text { History of } \\
\text { respiratory } \\
\text { disease }\end{array}$ & 3.186 & 1.3829 & 24.196 & 1.609 & 363.78 & $.021^{*}$ \\
\hline
\end{tabular}

Table 6. SLT Rehabilitation

\begin{tabular}{lllll}
\hline & Dysphagia Intervention & Number of participants implemented & Voice Intervention \\
\hline $\mathbf{1}$ & Oro-facial exercises & 3 & Vocal cord adduction exercises \\
$\mathbf{2}$ & Sensory stimulation & 2 & Vocal function exercises \\
$\mathbf{3}$ & Masako manoeuvre & 10 & Vocal hygiene \\
$\mathbf{4}$ & Effortful swallow & 12 & Respiratory support for phonation & 9
\end{tabular}




\begin{tabular}{lllll}
\hline & Dysphagia Intervention & Number of participants implemented & Voice Intervention & Nun \\
\hline $\mathbf{5}$ & Supraglottic swallow & 0 & EMST & 1 \\
$\mathbf{6}$ & Pitch glide & 3 & Other & 2 \\
$\mathbf{7}$ & Mendelsohn manoeuvre & 5 & & \\
$\mathbf{8}$ & Postural strategy & 6 & & \\
$\mathbf{9}$ & Chin tuck against resistance & 1 & & \\
$\mathbf{1 0}$ & EMST & 1 & & \\
$\mathbf{1 1}$ & NMES & 0 & & \\
$\mathbf{1 2}$ & Other & 17 & & \\
\hline
\end{tabular}

Abbreviations: EMST $=$ Expiratory muscle strength training, NMES= neuromuscular electrical stimulation 